NOTICE: this is the author's version of a work that was accepted for publication in Journal of Materials Processing Technology. Changes resulting from the publishing process, such as peer review, editing, corrections, structural formatting, and other quality control mechanisms may not be reflected in this document. Changes may have been made to this work since it was submitted for publication. A definitive version was subsequently published in Journal of Materials Processing Technology, Volume 140, Issues 1-3, September 2003, DOI:10.1016/S0924-0136(03)00751-9 


\title{
Cutting Performance of Diamond Tools During Ultra-Precision Turning of Electroless Nickel Plated Die Materials
}

\author{
A. Pramanik ${ }^{1}$, K. S. Neo ${ }^{1}, \mathrm{M} \mathrm{Rahman}^{1}$, X. P. Li ${ }^{1}$, M. Sawa ${ }^{2}$ and Y. Maeda ${ }^{2}$ \\ ${ }^{1}$ Dept. of Mechanical Engineering, National University of Singapore, 10, Kent Ridge Crescent, Singapore 119260 \\ TEL:+65-68744644 FAX:+65-6779-1459 E-MAIL: engp1490@nus.edu.sg \\ ${ }^{2}$ Production Engineering Research Laboratory, Hitachi ltd, Japan.
}

\begin{abstract}
This study is an attempt (a) to observe the wear characteristic of diamond tool with $200 \mathrm{~km}$ cutting distance and to study the effects of wear on the surface roughness and cutting forces and (b) to optimize various cutting parameters such as depth of cut, feed rate, spindle speed and phosphorus content. The experimental results showed that tool wear was not so significant although some defects on rake face were observed after cutting $15.6 \mathrm{~km}$. Further cutting showed that the surface roughness increases with cutting distance, and that the cutting forces were larger than thrust force at the beginning of cutting, but after cutting $130 \mathrm{~km}$ thrust force became larger and increased rapidly. It was also observed that forces increase with the increase of depth of cut, spindle speed and feed rate, and decrease with the increase of phosphorus content of the plating. Depth of cut has no significant effect on surface roughness, while it increases with increase of feed rate and decreases with the increase of percentage of phosphorus content in the workpieces. In case of spindle speed, surface roughness decreases with the increase of spindle speed up to a certain value and then starts to increase with the increase of spindle speed.
\end{abstract}

Keywords: Diamond turning, Ultra-precision machining, Tool wear, Electroless-nickel.

\section{Introduction}

Diamond tools are commonly used in ultra-precision machining of a number of hard materials to achieve nanometric surface finish. Tool wear in such applications is a very important factor as small tool wear can lead to significant degradation of surface quality. In die and molding applications, it was found that diamond tools are suitable for machining of Nickel-phosphorus plated molds to obtain mirror surface finish [1] and some studies have been carried out on machining of electroless nickel regarding tool wear characteristics for short cutting distance and changing workpiece materials. Some researchers [2] studied wear characteristics of two diamond tools with different infrared absorption quality for 70,000 feet $(20.9 \mathrm{~km})$ cutting distance of electroless-nickel and others [3] tried to make clear the relations of wear to various crystal orientations as well as to surface roughness in cutting aluminum alloy and nylon with the diamond tool. However, for very long cutting distance' wear characteristics of diamond tool and effects of cutting parameters and tool wear on surface finish and cutting forces are not well investigated, despite significant importance. The objectives of this paper are to study the performance of a single point diamond cutter at long cutting distance and to see the effect of various cutting parameters on the cutting performance; especifically surface roughness and cutting forces, on electroless-nickel plated die. The four parameters under study include depth of cut, feed rate, spindle speed and phosphorus content.

\section{Experiments}

In this study machining has been carried out on a TOSHIBA ultra precision machine Model ULG-100 using artificial diamond cutting tools with approximately $2 \mathrm{~mm}$ nose radius, $0^{0}$ rake angle, $7^{0}$ clearance angle and 110 crystal orientation under cutting condition given in Table 1.

Table 1

Cutting conditions for wear test.

\begin{tabular}{|l|l|l|l|}
\hline Depth of cut & Feed rate & Spindle speed & $\%$ P content \\
\hline $4 \mu \mathrm{m}$ & $10 \mu \mathrm{m} / \mathrm{rev}$ & $1000 \mathrm{rpm}$ & $9-13 \mathrm{w} / \mathrm{w}$ \\
\hline
\end{tabular}

The workpiece material was electroless-nickel of $100 \mu \mathrm{m}$ plating thickness, which was plated on Starvax disc of $100 \mathrm{~mm}$ diameter with a recess of $5 \mathrm{~mm}$ diameter at the center. During cutting the tool was moved from the periphery to the center of workpiece and experimental data were taken after $1^{\text {st }}, 2^{\text {nd }}, 5^{\text {th }}, 10^{\text {th }}, 20^{\text {th }}, 50^{\text {th }}$ passes and then after every 15 passes up to $260^{\text {th }}$ pass and manual observation was performed after every pass.

To see the influence of the depth of cut, feed rate, spindle speed and different phosphorus contents on the surface finish and cutting forces same machine and cutting tool were used with facility of rotating the cutting tools laterally so that different portions of the cutting edge can be employed for each cutting pass to minimize the effects of tool wear. The parameter matrixes for the experimental studies are given in Table 2. 
Vacuum suction and spray mist (Kerosene based) were used for proper cutting and removing of chips during experiments.

Table 2

Machining conditions to see the effects of cutting parameters.

\begin{tabular}{|c|c|c|c|c|}
\hline $\begin{array}{c}\text { Exp } \\
\text { No. }\end{array}$ & $\begin{array}{c}\text { Depth } \\
\text { of cut } \\
(\mu \mathrm{m})\end{array}$ & $\begin{array}{c}\text { Feed rate } \\
(\mu \mathrm{m} / \mathrm{rev})\end{array}$ & $\begin{array}{c}\text { Spindle } \\
\text { speed } \\
(\mathrm{rpm})\end{array}$ & $\begin{array}{c}\text { Phosphorus } \\
\text { content } \\
(\% \mathrm{w} / \mathrm{w})\end{array}$ \\
\hline 1 & 2 & 10 & 1000 & 9.57 \\
\hline 2 & 4 & 10 & 1000 & 9.57 \\
\hline 3 & 7 & 10 & 1000 & 9.57 \\
\hline 4 & 10 & 10 & 1000 & 9.57 \\
\hline 5 & 4 & 2 & 1000 & 8.47 \\
\hline 6 & 4 & 10 & 1000 & 8.47 \\
\hline 7 & 4 & 30 & 1000 & 8.47 \\
\hline 8 & 4 & 50 & 1000 & 8.47 \\
\hline 9 & 4 & 10 & 100 & 10.23 \\
\hline 10 & 4 & 10 & 500 & 10.23 \\
\hline 11 & 4 & 10 & 1000 & 10.23 \\
\hline 12 & 4 & 10 & 1500 & 10.23 \\
\hline
\end{tabular}

For all the experiments, measurements and observations made included:

a) Plunge cuts on oxygen free high conductivity copper were performed before and after every experiment to observe any change in tool profile during cutting.

b) Measurement of hardness (Hv) to see its effects on machining,

c) Optical observation of the cutting tools and electrolessnickel surface with nomarski microscope.

d) Every machined surface was measured with a telystep stylus profiler with an added computer data acquisition system for calculation of the arithmetic mean surface roughness $\left(\mathrm{R}_{\mathrm{a}}\right)$ and the flatness $\left(\mathrm{P}_{\mathrm{t}}\right)$.

e) Cutting force and thrust force were measured during machining with a Kistler piezoelectric 3-componenet dynamometer in conjunction with a Kistler 3-channel charge amplifier and a recorder to record the forces. The dynamometer was set for a maximum cutting force of 5.0 Newton.

\section{Result and discussion}

\subsection{Cutting tool wear and cutting distance}

Diamond is the hardest material and electroless-nickel is chemically inert, the inertness arises from the absence of geometric defects, as has been suggested to explain the high resistance which some materials exhibit in amorphous state [5], so possibility of any wear is very low. However, some wear had appeared at rake face and flank face and spread to some extent with a sequence of repeated cutting, for total cutting distance of $202 \mathrm{~km}$. The possible wear progression process at rake face can be seen in Fig. 1. It is clear from the picture that the defect arose at rake face after cutting $7.8 \mathrm{~km}$ and the wear developed clear shape after cutting $39 \mathrm{~km}$ and after this the defective zone was nearly unchanged up to $202.8 \mathrm{~km}$ cutting distance. This type of wear at rake face is quite interesting which is difficult to classify. The EDX analysis showed no material deposition at rake face and it is not possible to get a complete surface topography of the wear zone as the area is too large for the AFM (Atomic Force Microscope) and too small for telystep stylus profiler. The causes and nature of this type of wear are under investigation.
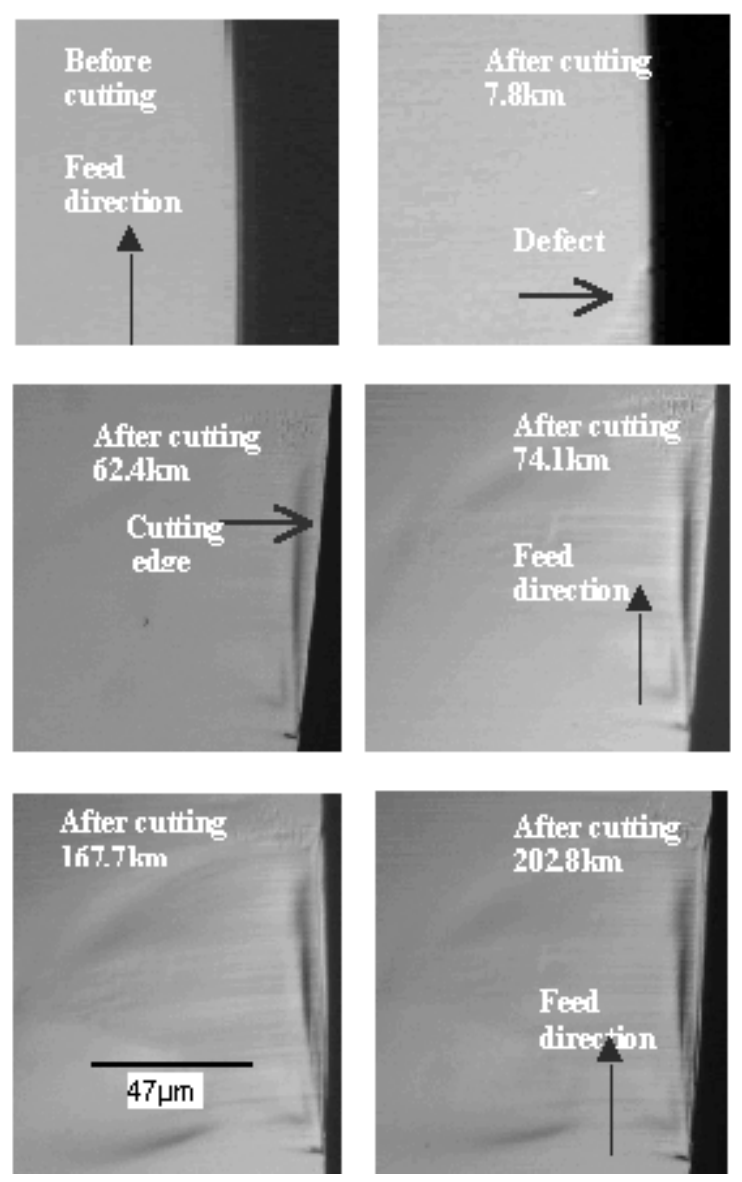

Fig. 1. Rake face (X500) at different cutting distance. (From Nomarsky microscope)

In case of the flank face some wear appeared after cutting $15.6 \mathrm{~km}$ as a bright line through the cutting edge at flank face, which was not detectable by SEM. Some groves spaced at $10 \mu \mathrm{m}$ were also noticed across the bright line of cutting edge. This type of wear may be termed as wear of stepped form. Uncut portion of workpiece due to worn cutting edge causes the growth of stepped wear in the following manner. As the cutting distance increases, a portion of cutting edge worn out and the uncut or low depth of cut potion arise on the workpiece. This portion of workpiece is then removed by adjacent cutting edge, thus a secondary wear zone is created. The width of material removal is identical as feedrate is same but depth of cut for first wear zone is higher than that of second wear zone [3]. With the increase of cutting distance groves were more evident. The pattern of wear progression is shown by the picture sequence of Fig. 2, and the behavior of wear can be shown by the graph at Fig. 3 .

After cutting $202.8 \mathrm{~km}$ the amount of wear is only $4 \mu \mathrm{m}$, the wear increase with the increase of cutting distance.

\subsection{Machined surface and cutting distance}

The machined surface is nothing but replica of tool profile and any change in cutting edge profile will affect the machined 
surface. The effect of cutting distance on surface can be clearly viewed from Fig. 4. At the start of cutting the surface carries
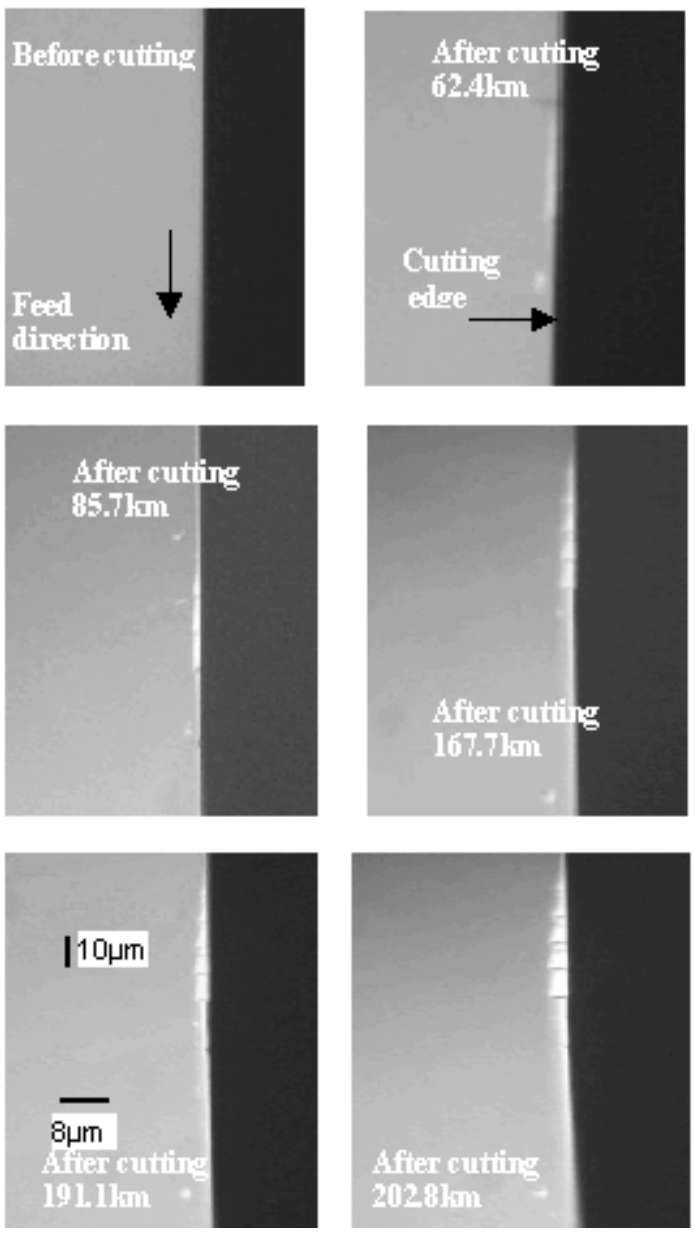

Fig. 2. Flank face (X500) at different cutting distance. (From Nomarsky microscope)

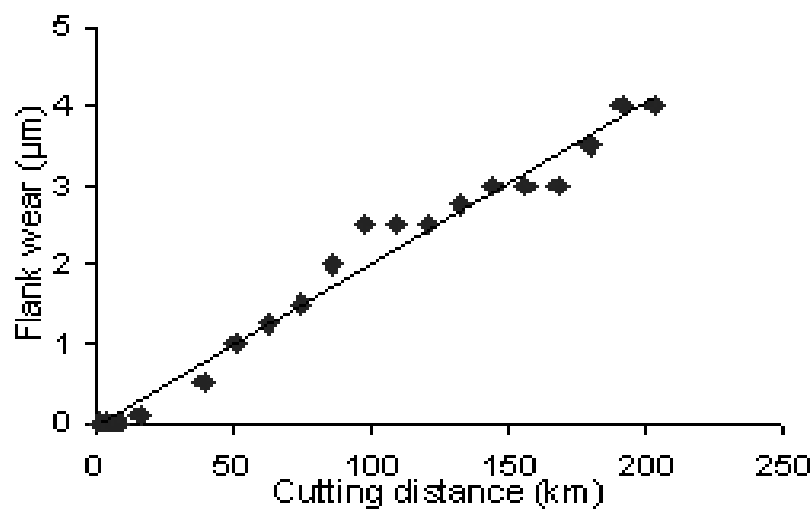

Fig. 3. Effects of cutting distance on flank wear.

only feed marks but after cutting $156 \mathrm{~km}$, some lines appear between feed marks and these lines became more prominent at the end of cutting. These lines may be the result of stepped wear at the cutting edge of flank face as this portion of cutting edge is associated with surface finish, residual stress, friction and subsurface plastic flow [4].
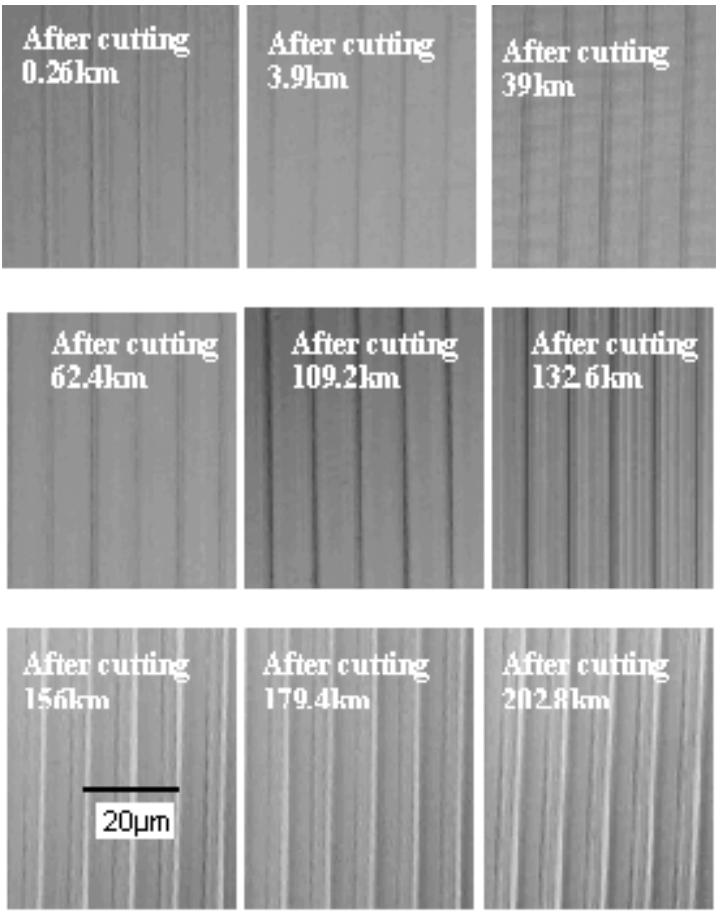

Fig. 4. Picture of surface (X500) at different cutting distance. (From Nomarsky microscope)

The theoretical surface roughness for a machined surface can be calculated for single point diamond tool approximately by the formula,

$\mathrm{R}_{\mathrm{z}}=\mathrm{f}^{2} / 8 \mathrm{R}, \quad \mathrm{R}_{\mathrm{a}}=0.032 \mathrm{f}^{2} / \mathrm{R}$

Where $\mathrm{f}=$ feed rate, $\mathrm{R}=$ tool nose radius and $\mathrm{R}_{\mathrm{z}}=$ maximum individual peak to valley height. $R_{a}=$ average roughness.

In general, the surface roughness depends on many other factors such as tool wears, workpiece material, machine stiffness, cutting edge sharpness, machining conditions etc. In this section we are concern only with tool wear that is very much dependent on cutting distance assuming other factors constant. The effect of cutting distance on surface roughness can be presented by the graph at Fig. 5. From the figure it is clear that the rate of increase of average roughness $\left(R_{a}\right)$ is very small with the cutting distance but in increasing mode.

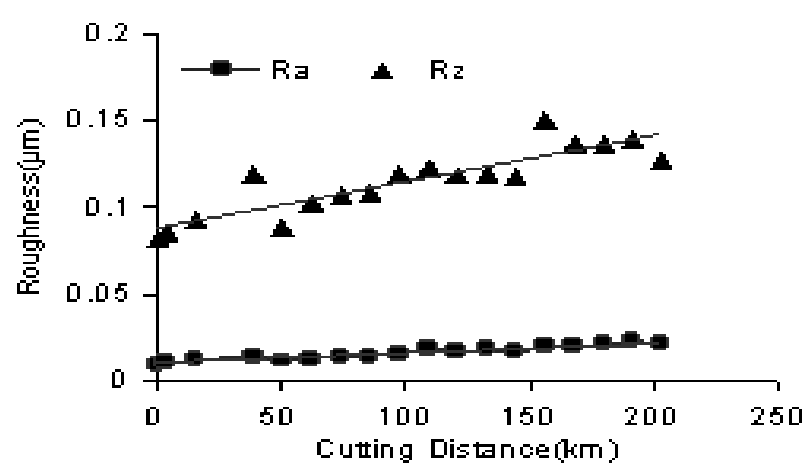

Fig. 5. Effects of cutting distance on surface roughness.

$\mathrm{R}_{\mathrm{z}}$ is showing a little irregular behavior with the cutting distance and does not give any conclusive result but it can be said that $R_{z}$ 
is also in increasing mode if all the points are added by best-fit curve.

\subsection{Machining forces and cutting distance}

Fig. 6 shows the relation of machining forces and cutting distance. From the graph it is clear that initially cutting force was higher than thrust force but after cutting nearly $110 \mathrm{~km}$ thrust force crossed the line of cutting force and it became higher than cutting force. In the whole cutting distance cutting force did not change so much, it was more or less constant but thrust force increased much after cutting around $110 \mathrm{~km}$ and it was in increasing mode. With the increase of cutting distance the cutting edge radius may have increased because of wear and this increased cutting edge radius creates negative rake which makes the thrust force higher as described in the Fig. 7. The Fig. 7a shows the cutting geometry at the start of cutting and $7 \mathrm{~b}$ shows the cutting geometry after cutting $110 \mathrm{~km}$ where $F_{t}$ and $F_{c}$ are thrust force and cutting force respectively.

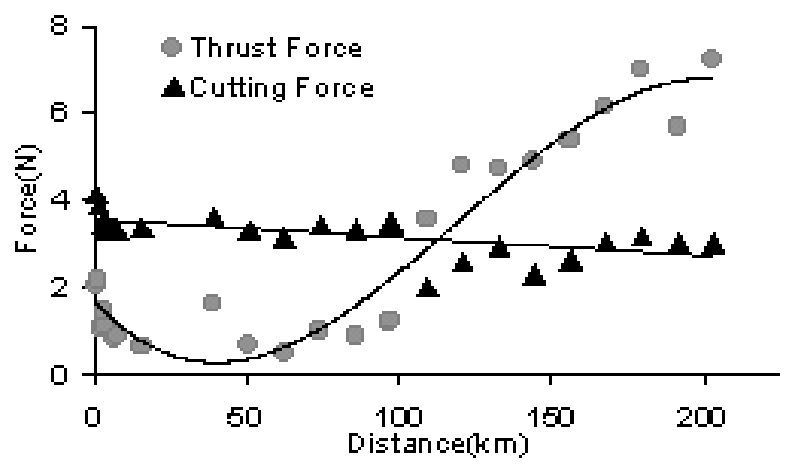

Fig. 6. Effect of cutting distance on machining forces.

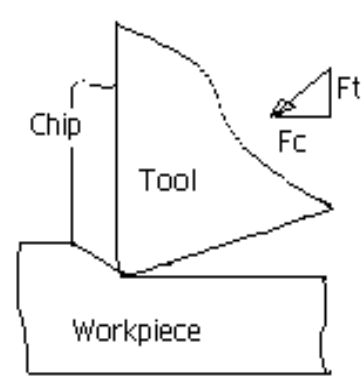

(a)

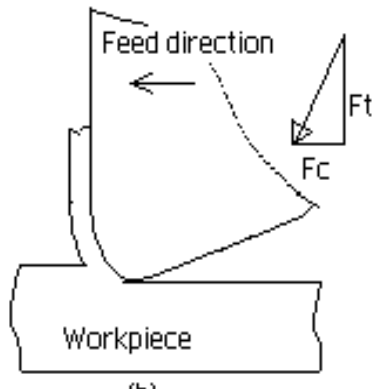

(b)
Fig. 7. Effect edge radius on cutting mechanism.

\subsection{Effect of depth of cut on surface finish}

Surface roughness $\left(R_{a}\right)$ was observed with the variation of depth of cut keeping other factors constant and the plot of surface roughness versus depth of cut is given in Fig. 8. The figure shows very irregular behavior of surface roughness with depth of cuts and it seems that depth of cuts do not play any important role on surface roughness in this range.

Observation under the nomarski microscope did not show any surface damage. Electroless-nickel is a brittle material and for such materials there is a critical depth of cut for transition to brittle mode from ductile mode cutting [6,7]. In this instance it seems that the critical depth of cut for electroless-nickel is above 10 micron.

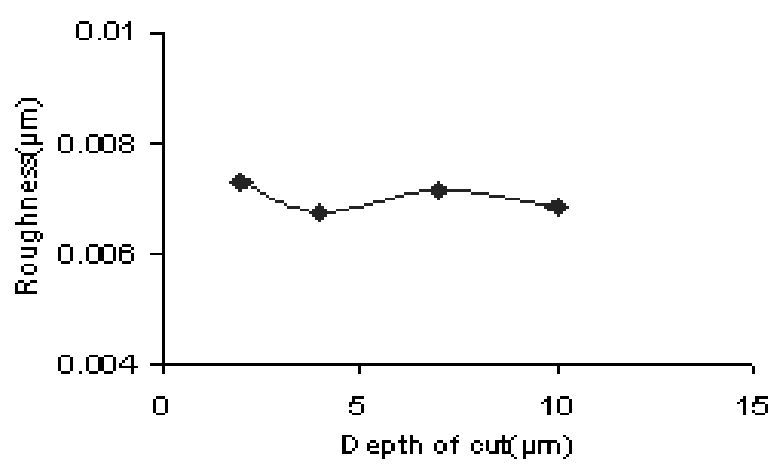

Fig. 8. Effect of Depth of Cut on Surface Roughness.

\subsection{Effect of feed rate on surface finish}

Feed rate plays a very important role in machining economics and surface finish. In the facing operation, the surface roughness profile across the diameter of the workpiece is determined by tool geometry and feed rate. The surface roughness profile can be considered as successive movements of the tool profile at intervals of tool feed. Surface roughness of ultra-precision machining is largely influenced by machine kinematics at high feed rate, but significantly influenced by other factors at lower feed rate [8]. In this study surface roughness increases rapidly with the increase of feed rate and the plotting of surface roughness $(\mathrm{Ra})$ versus feed rate is shown in the fig. 9. With the increase of feed rate the tool profile marks become prominent on the surface, as the cutting of preceding profile by the successive cutting is less, which results in poor surface finish. It is also believed that with the increase of feed rate elastic deformation increases and cutting process goes toward brittle mode machining [9].

\subsection{Effect of spindle speed on surface roughness}

The effect of spindle speed on surface roughness $(\mathrm{Ra})$ is shown in Fig. 10. In the first stage, the surface roughness is in decreasing trend by very high rate with the increase of spindle speed and after certain limit surface roughness increases very slowly with the increase of spindle speed.

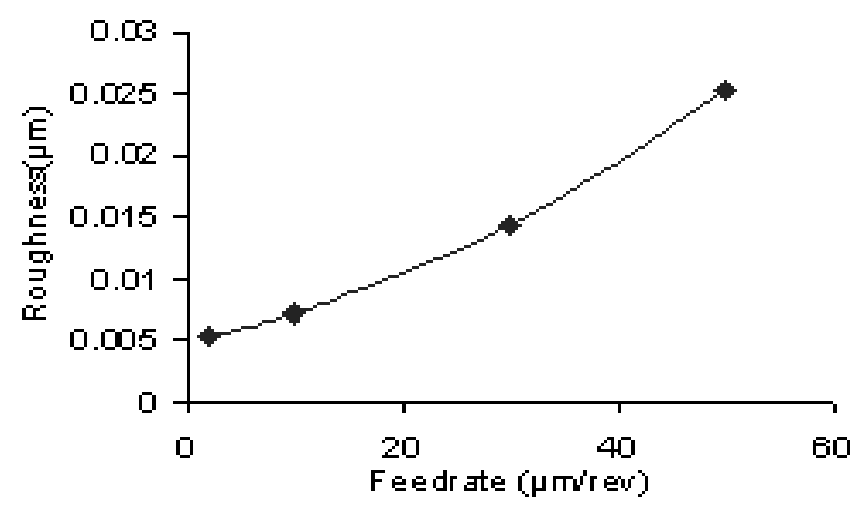

Fig. 9. Effect of Feed rate on Surface Roughness. 
With the increase of spindle speed, the width of shear zone decreases, which leads to less stress propagation, small deformation zone and ductile mode cutting [4]. However with further increase in spindle speed, the vibration of the machine may increase, hence adversely affecting the cutting process resulting in a poor finish.

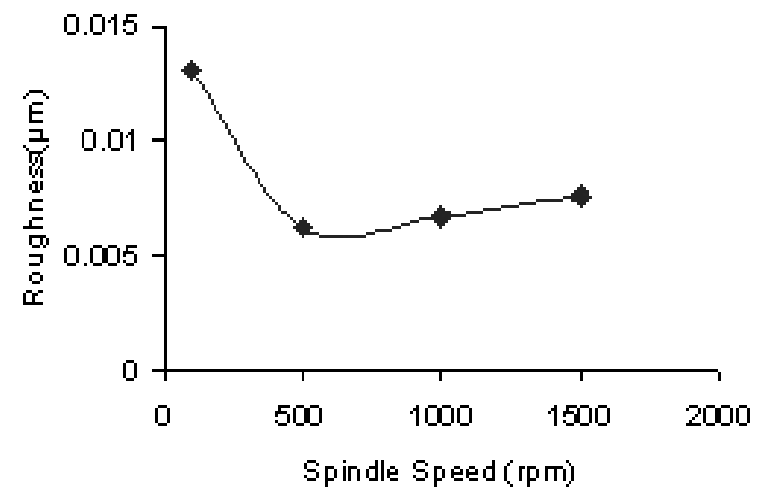

Fig. 10. Effect of Spindle Speed on Surface.

\subsection{Effect of phosphorus content on surface finish}

Fig. 11 shows that surface roughness decreases with the increase of phosphorus content and this may be due to less hardness and more ductile behavior of electroless-nickel with high phosphorus content $[2,10]$.

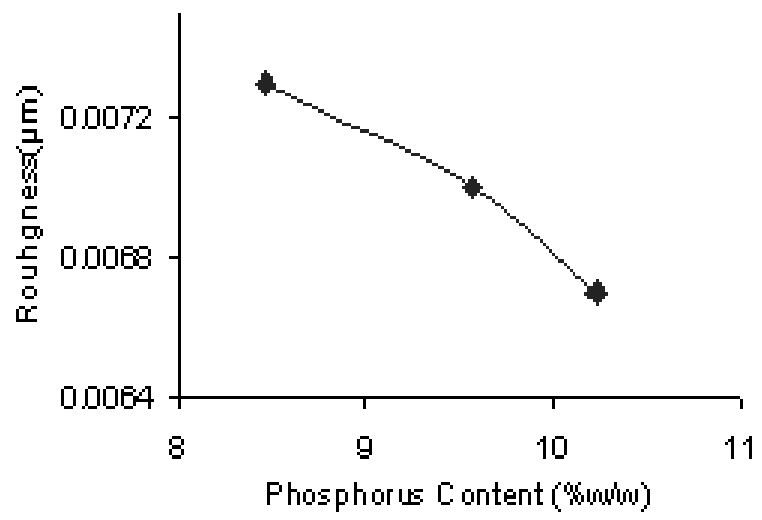

Fig. 11. Effect of phosphorus content on roughness.

The phosphorus in the electroless-nickel is likely to act as lubricant and this may be a consideration for using higher phosphorus content to get a better surface finish.

\subsection{Forces during machining}

The two components of forces measured were- (a) Cutting force; normal to cutting tool face, and (b) Thrust force; normal to work piece surface. Both of these forces are presented in fig. 12 to Fig. 15, which show the variation of these forces with the machining parameters at the beginning of each cutting pass.

The figures indicate that both of these forces increased with the increase of depth of cut, feed rate and spindle speed, and forces decreased with the increase of phosphorus content of workpieces. With the increase of depth of cut and feed rate, more stresses are created on the cutting tool as greater forces are required to

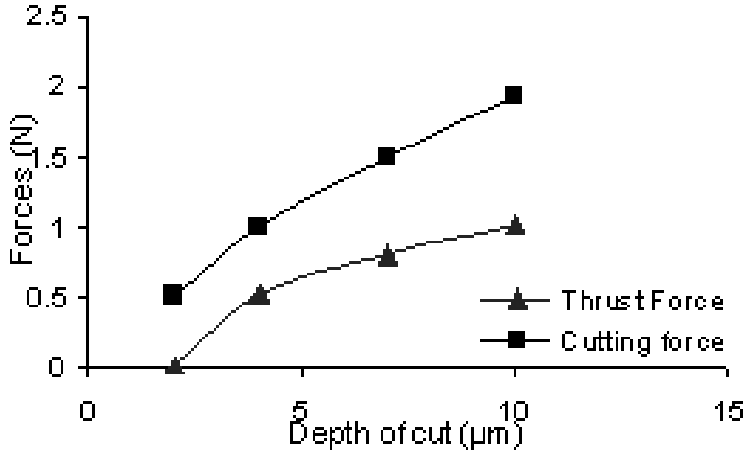

Fig. 12. Effect of Depth of cut on Forces.

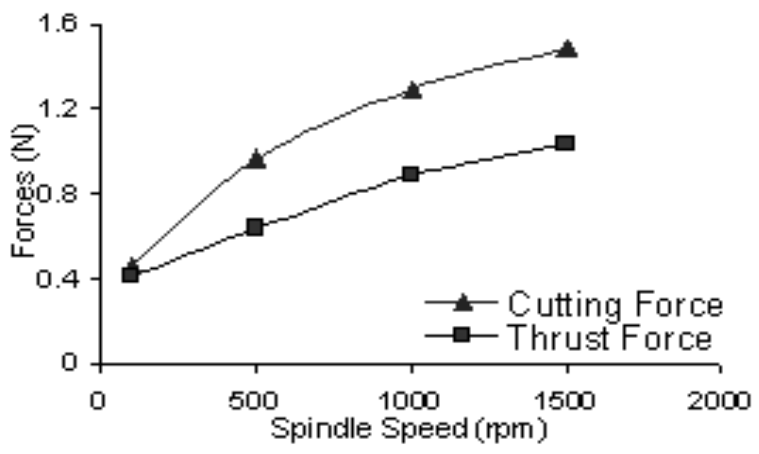

Fig. 13. Effect of Spindle Speed on Forces.

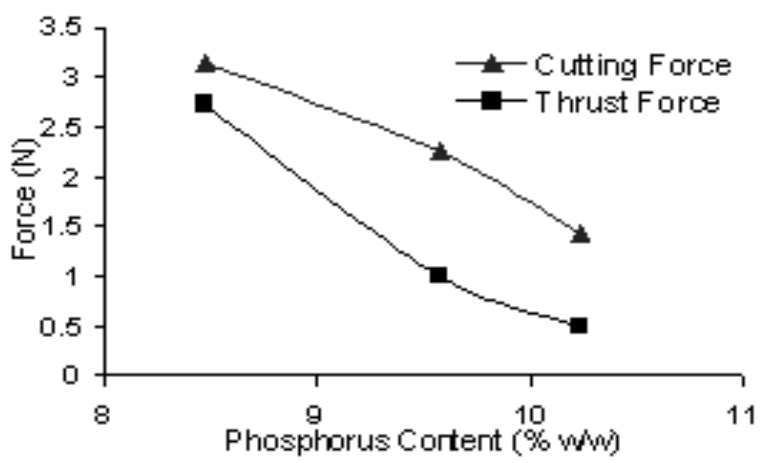

Fig. 14. Effect of Feed rate on Forces.

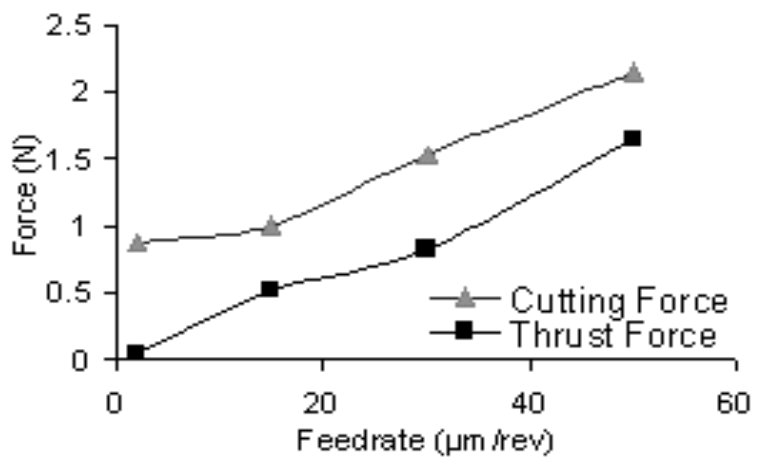

Fig. 15. Effect of Phosphorus Content on Forces.

remove more materials from the workpieces. For the increase of spindle speed, the material removal rate increase resulting in the 
increase of machining forces. Increased phosphorus content of the workpiece makes it softer, which causes low machining forces with higher phosphorus content.

\section{Conclusions}

The behavior of a diamond cutter with long cutting distance and it's effect on surface roughness and machining forces have been studied. The effect of four experimental parameters (depth of cut, spindle speed, feed rate and phosphorus content) also has been studied in this work. The conclusions that can be drawn from this study are:

a) Long distance (up to $200 \mathrm{~km}$ ) diamond cutting of electrolessnickel is possible. At the end of machining the surface roughness is still mirror finish and very low tool wear has been observed at flank face.

b) Surface roughness of electroless-nickel (phosphorus content 9.59 percent $\mathrm{w} / \mathrm{w}$ ) is not affected significantly by variation of depth of cut $(1 \mu \mathrm{m}-10 \mu \mathrm{m})$. Higher phosphorus content gives better surface.

c) Surface roughness increases rapidly with the increase of feed rate.

d) There is a critical value of spindle speed for which best surface finish can be achieved.

e) It seems that after cutting some distance the cutter edge radius increases resulting in negative rake angle hence developing higher thrust force.

f) Cutting force and thrust force increase with the increase of depth of cut, spindle speed and feed rate but decrease with the increase of phosphorus content.

\section{Reference:}

1. J. M. Casstevens and C. E. Daugherty, "Diamond turning of surfaces on electroless nickel", in Precision Machining of T. T. Saitoed., Proc. SPIE159, 109(1978)

2. C. K. Syn, J. S. Taylor and R. R. Donaldson, "Diamond tool wear vs. cutting distance on electroless nickel mirrors", SPIE vol.676 Ultrprecision Machining and Automated Fabrication of Optics, 1986.pp-128-140

3. R. Wada, H. Kodama, K. Nakamura, "Wear characteristics of single crystal diamond tool",Annals of CIRP vol.29/1/1980, p47-52

4. Amitabha Bhattacharyya, "Metal Cutting- Theory and Practice", New Central Book Agency (P) Ltd, 8/1 Chintamoni Das Lane, Calcutta 700009, India.

5. Hitchiner M. P., Wilks J., "Factors affecting chemical wear during machining", Wear, Vol-93, 1984, pp63-80.

6. Moriwaki, T., Shamoto, E. Inoue, K., "Ultraprecision Ductile cutting of Glass by applying Ultrasonic Vibration", Annals of CIRP,41(1) 1992,pp141-144.

7. Glenn O. Mallory, Juan B, Hajdu, "Electroless plating : fundamentals and applications", Chapter-4, sponsored and published by American Electroplaters and Surface Finishers Society.(1990)

8. N. P. Hung, Z. W. Zhong, K. K. Lee, C. F. Chai, " Precision grinding and facing of copper- beryllium alloys", Precision Engineering 23(1999) 293-304.

9. Jun Qian, Hitoshi OHMORI, WeiLI and B. P Bandyopadhyay, " High Efficiency and Precision

Grinding of Ferrite with the Application of ELID

(Electrolytic In-process Dressing), Int. J. Japan

Soc. Pre. Eng., Vol.33, No.1 (Mar 1999)

10. L. F. Spencer, "Electroless Nickel Plating- A Review", Metal Finishing, 72, 58(Dec. 1974) 